\title{
UNE AFFIRMATION INEXACTE DE BOGDANOFF A PROPOS DE MES RECHERCHES SUR LE LAIT STÉRILISÉ A HAUTE TEMIPÉRATURE
}

\author{
par le Prof. Dr méd. Costantino GORINI \\ Directeur du Laboratoire de l'Ecole supérieure d'agriculture \\ de Bactériologie de Milan.
}

Bogdanoff, dans un travail paru dans cette Revue (Le Lait, juin $1933,13,677$ ) où il démontre, à l'appui de la méthode de numération bactérienne directe de DREYER-KoRoLYefF, que le chauffage préalable du lait à des températures fortes élevées (jusqu'à $120^{\circ} \mathrm{C}$.) le rend un bon milieu de culture pour les microbes acido-lactiques du type Streptococcus lactis et Bacterium Casei, a l'obligeance de citer mon nom. C'est un agrément qui ne m'arrive pas souvent; toutefois je trouve que c'est bien moins désagréable de n'être pas mentionné du tout que de l'être d'une manière inexacte, comme c'est le cas présent.

BOGDANOFF m'attribue l'opinion que "le chauffage du lait à haute température le dénature à un tel point que le développement des bactéries qui y seraient ensemencées est retardé ").

Or, cette affirmation est tout à fait inexacte, et cela pour deux raisons. En premier lieu, mes recherches ne s'occupent pas de développement des bactéries, c'est-à-dire de leur multiplication, mais de la manifestation de leurs fonctions. En deuxième lieu, mes recherches ne s'occupent pas de microbes acido-lactiques du type Streptococcus lactis et Bacterium Casei, ni d'autres bactéries, mais exclusivement des Acidoprotéolytes Gorini.

Et j'ai toujours soutenu depuis 1917 (Rend. R. Acc. Lincei, $1917,26,195$ et 223), comme je le soutiens encore, que le lait stérilisé à l'autoclave à des températures supérieures à $100^{\circ} \mathrm{C}$. est impropre à l'explication des activités caséolytiques de ces bactéries. En me bornant aux publications que j'ai faites en langue française, il me suffira de rappeler ce que j'écrivais dans cette même Revue en 1921 (Le Lait, 1921, I, 57) : "En général, on a l'habitude, ainsi qu'on l'apprend par les Traités de bactériologie laitière 'FrEUdENREICH, ORLA-JENSEN, etc.), de stériliser le lait très profondément à l'autoclave, de manière qu'il prenne une teinte brunâtre ; or, précisément dans un tel état, le lait est impropre à déceler l'activité protéolytique des ferments lactiques; au contraire, le lait qui a été stérilisé modérément de manière à conserver sa teinte blanche presque inaltérée est très convenable. A l'aide des cultures dans du lait stérilisé blanc, j'ai pu constater le pouvoir caséolytique chez plusieurs ferments lactiques qui, dans le lait stérilisé brunâtre, en semblaient dépourvus. En cela, se trouve sans doute la raison pour 
laquelle les auteurs n'ont observé aucune propriété caséolytique ou seulement une propriété caséolytique transitoire chez certains types de ferments lactiques auxquels, bien entendu, contrairement à mon opinion, ils n'ont attribué aucun rôle dans la maturation du fromage. ”

Et dans mon rapport au Congrès international de Laiterie 1931, à Copenhague, j'écrivais : "Dès 1917 (Rend. R. Acc. Lincei, 1917, 26, 195 et 223) j'ai montré que les températures supérieures à $100^{\circ} \mathrm{C}$, et plus particulièrement le procédé ordinaire de stérilisation en autoclave à $115^{\circ}-120^{\circ} \mathrm{C}$, rendent le lait impropre à la culture de certains types de bactéries et, notamment, annihilent leur activité acidoprotéolytique, par exemple, celle du Mammococcus; de là la difficulté d'observer les manifestations de cette activité dans le lait traité à l'autoclave et la nécessité de stériliser le lait par tyndalisation à $100^{\circ} \mathrm{C}$. ».

J'ai exposé aussi dernièrement les mêmes idées dans le volume jubilaire pour Charles Porcher. (C. GorinI. Les acidoprotéolytes dans la science et dans la pratique.)

Je ferai remarquer en outre que mes observations concernent tout spécialement des Acidoprotéolytes très délicats, tels que les types parasites ou semiparasites comme le Mammococcus Gor, le Gastrococcus Gor., I'Enterococcus, le B. Minimum mammae Gor., (syn. B. pyogènes) les streptocoques pathogènes, certaines races de B. Coli et d'autres, qui sont particulièrement exigeants en protéines natives pour l'explication de leurs pouvoirs enzymatigues. Du reste, les connaissances enzymologiques sont bien suffisantes à nous faire comprendre que pour déceler et étudier chez. les bactéries la production et l'action de chymases et de protéases, comme celles des acidoprotéolytes (1), il est nécessaire d'offrir à ces germes de la caséine la plus pure possible, c'est-à-dire le moins possible modifiée par la chaleur (2).

Peut être BogdANOFF se rapporte à mes recherches sur le lait disgénésique, où j'ai envisagé moi aussi l'accroissement des germes par des énumérations bactériennes; mais cela a trait, non au lait chauffé, mais au lait cru, en raison des modifications qu'il peut

(1) Gorrnr, C. - Atti Pont. Ace. Se. Nuori Lincei, 1932, 85, 29.

Gorrn, C., Grassmann, W., Sehleich, H. - Zeits. Physiol. Chemie, 1932, 205, 133.

(2) C'est par cette précaution que j'ai pu démontrer l'action eaillante du Streptococcus pyogenes, tandis que ORLA-Jensen (The lactic acid bacteria-Copenhagen, 1919) le déclare non-caillant. Pourtant dernièrement (C. f. Bakt. II Abt, 1930, 80, 331). OrLA-Jensen même a reconnu que pour certains streptocoques (Streptoc, mastitidis, Str. cremoris, Str, liquefaciens) le lait stérilisé à $100^{\circ} \mathrm{C}$. est préférable au lait stérilisé à $115^{\circ} \mathrm{C}$. A une conclusion analogue arrivent Frazier et RupP (Journ. Bacter. 1928, 16, 65) au sujet des bactéries protéo. lytiques plus délicates. Aussi les investigations récentes de Davis et Mattick sur le métabolisme azoté des ferments lactiques (Journ. Dairy Res. 1932, 4, 81) viennent à l'appui de mes anciennes recherches. 
présenter $a b$ origine dans sa valeur nutritive. En effet la manière différente de se comporter des acidoprotéolytes dans le lait, suivant son origine, m'a conduit à faire ressortir qu'il n'y a pas un lait, mais des laits. Dès 1907 (Rend. R. Ist. Lom. Sc. Lett., 1907, 40, 947) j'ai montré l'existence de laits qui, bien que normaux à l'aspect et à l'analyse chimique et micrographique ordinaire, bien qu'ayant subi le même traitement quant à la stérilisation et à l'incubation, se comportent différemment vis-à-vis d'une même bactérie. Il y a même des laits, que j'ai appelés précisément disgénésiques (Rend. R. Acc. Lincei, 1927, 6, 338. Le Lait 1928, 8, 465), tout à fait impropres à la culture de certains ferments lactiques ou acidoprotéolytiques. Parmi les facteurs naturels capables de modifier la valeur nutritive du lait j'ai indiqué les différences de races, de nourritures données aux vaches, leurs différentes périodes de lactation, et la différence dans le pouvoir microbicide de leur lait, pour autant que ce pouvoir microbicide ne soit pas complètement détruit par le procédé de stérilisation, ou encore, les différences dans la microflore mammaire qui, même normalement, est très variée en quantité et en qualité et, dans un même lait, peut souvent différer suivant les parties de la traite. On pourrait ainsi expliquer comment diverses épreuves d'un même lait sont susceptibles, dans des conditions identiques, de donner des résultats différents bien qu'avec une même bactérie. J'ai aussi constaté alors que les laits disgénésiques peuvent être rendus eugénésiques par l'addition de substances stimulantes agissant comme catalysateurs (peptone, extrait de viande ou de levure, sang, vitamines, etc.). De tout cela, j'en ai tiré la nécessité que l'étude de l'action des bactéries sur le lait soit fondée sur l'examen de plusieurs cultures ayant chacune, pour base, des laits différents.

J'aurais autre chose à ajouter ; cependant je pense avoir donné des éclaircissements suffisants pour amener mon cher collègue BOGDANOFF non seulement à rectifier son affirmation sur mon opinion, mais aussi à tomber d'accord avec mes travaux, que vraisemblablement il n'a pas eu l'occasion de lire, puisqu'il n'en cite aucun.

Milan, 1 er juillet 1933. 